\title{
Projeto Monumenta: filosofia e práticas em interface com o turismo
}

\author{
Monumenta Program: \\ filosophy and praxis in interface with tourism
}

Susana Gastal

RESUMO: O Programa Monumenta é uma iniciativa-do governo federal que propõe recuperar os centros históricos de 27 cidades brasileiras, a exemplo do que já aconteceu com o Pelourinho, em Salvador (Bahia). A filosofia do Programa concretiza-se a partir de quatro eixos: sustentabilidade, visibilidade, atratividade e acessibilidade. Por suas implicaçōes diretas com o turismo, faz-se urgente um maior diálogo e participação dos setores e dos profissionais desta área, no seu planejamento e implantação, em especial quando se pensa em turismo com responsabilidade social e culturalmente sustentável. $\mathrm{O}$ artigo centra-se na análise do Programa, em especial na formulação e nos documentos legais que embasaram a sua aplicação em Porto Alegre/RS.

PALAVRAS-CHAVE: turismo; turismo urbano; turismo cultural; centros históricos; Porto Alegre.

ABSTRACT: "Monumenta" is a Brazilian (Federal) Government Program that aims to preserve historical centers of 27 Brazilian cities, as it has already happened with Pelourinho, in Salvador, BA. The Program is based on 4 coordinates: sustainability, visibility, attractiveness and accessibility. Because it is directly involved with tourism, it is urgent that all professionals and

1. Mestre em Artes Visuais/UFRGS e doutora em Comunicaçāo Social/PUCRS. É professora do Curso Superior de Turismo, da FAMECOS/PUCRS, da graduaçāo e do mestrado em Turismo da Universidade de Caxias do Sul (Caxias do Sul/RS). Contato: Rua Francisco Getúlio Vargas, 1130 95070-560 - Caxias do Sul-RS; e-mail: sgastal@terra.com.br 
institutions involved with the area should engage in a wider conversation. Especially if the goal is a tourism that deals with social responsibility. This paper describes the Program Porto Alegre/RS version.

KEYWORDS: tourism; urban tourism; cultural tourism; historical centers; Porto Alegre.

\section{Introdução}

O Projeto Monumenta é uma iniciativa do governo federal que propõe realizar vultosos investimentos, nos próximos anos, em 27 cidades brasileiras, com o objetivo de resgatar os centros históricos locais, a exemplo do que já aconteceu com o Pelourinho, em Salvador (Bahia). A proposta será adequada a cada uma das localidades, mas com uma mesma filosofia, que se embasa menos em questões histórico-culturais das localidades e mais naquilo que os documentos oficiais do Projeto têm caracterizado como sustentabilidade, visibilidade, atratividade e acessibilidade.

Ao não priorizar o enfoque cultural e identitário das localidades e trabalhar em seu planejamento com questões implicitamente turísticas - como se procurará demonstrar ao longo deste artigo -, o Projeto Monumenta parece encaminhar questionamentos de cunho e implicações de responsabilidade social sobre os quais os segmentos profissional e acadêmico do Turismo parecem não ter sido consultados, mas sobre os quais, provavelmente, virão a responder.

Por meio da análise de documentos técnicos e de entrevistas com profissionais ligados ao Programa e ao IPHAN (Instituto do Patrimônio Histórico e Artístico Nacional), o presente artigo busca descrever a proposta do Programa Monumenta tal como vem sendo viabilizada em Porto Alegre, e como um indício do que poderá ocorrer nas demais cidades submetidas à sua intervenção, pois ainda que os projetos e os contratos obedeçam a especificidades locais, as diretrizes do órgão financiador e dos consultores internacionais parecem ser os mesmos em todas as localidades.

\section{Monumenta: antecedentes históricos}

O Programa Monumenta foi apresentado aos porto-alegrenses com a seguinte explicação:
(...) o Programa Monumenta está inserido no Programa de Revitalização da Área Central. A palavra Monumenta vem do latim e sua tradução é "monumentos". A origem é o verbo "monere", que significa lembrar. E esta é a proposta do programa: manter viva, na cidade, a lembrança de pessoas, fatos ou lugares que tenham valor e significado histórico e cultural ${ }^{2}$.

Esta apresentação faz parte do folheto que a Prefeitura Municipal de Porto Alegre utiliza para divulgar um Programa de origem federal, nascido de uma parceria do Ministério da Cultura com o Banco Interamericano de Desenvolvimento - BID, que ainda conta com a assinatura da Unesco, órgão da Organização das Nações Unidas para tratar dos assuntos culturais. O Banco entra como financiador, que terá no Brasil a Caixa Econômica Federal como gestor; o Ministério, com a coordenação do Programa dentro do país; e a Unesco com o "apoio técnico", subterfúgio burocrático para fugir à Lei de Licitação - que obriga a consulta pública para compras e contratação de serviços -, repassando as verbas, via convênios, ao órgão internacional que, para efeitos legais, será quem contratará (e pagará) os técnicos envolvidos no projeto dentro do país.

O interesse do BID pelo patrimônio histórico teria surgido em 1988 quando, após um grande terremoto, a cidade de Quito, Equador, precisou ser reconstruída e seus prédios históricos restaurados, e o Banco participou dos trabalhos como órgão financiador das ações. A experiência equatoriana teria rendido dividendos em termos da imagem pública ao agente financeiro, num momento em que o patrimônio surgia como vedete no bojo da nova relação pós-moderna com o passado.

Em 1995, Francisco Iglesias, presidente do BID, ao visitar Olinda com membros do Ministério da Cultura e da Unesco, teria ficado sensibilizado com a situação do patrimônio arquitetônico local - de alto valor cultural, mas em estado precário de conservação - e aquiescido em criar linhas de crédito específicas para sua recuperação, utilizando, para tanto, o modelo da bem-sucedida experiência equatoriana.

No Equador, o plano de recuperação do patrimônio histórico chamava-se Fondo de Salvamiento del Patrimonio Cultural:

Quando entrou o BID, este programa já tinha resultados reconhecíveis. E o Banco passou a entrar com dinheiro porque viu que havia mercado para outro tipo de negócio, unindo patrimônio e turismo. O BID entrou com 40 milhões de dólares, e o FONSAL, com 11 milhões. As gestões iniciaram em 1989 e os recursos chegaram depois. Os componentes do programa incluíram melhoramento de áreas públicas, estacionamentos, equipamentos

2. Prefeitura Municipal do Porto Alegre. Programa Monumenta Porto Alegre, s/d. (folder) 
urbanos, reabilitação do setor privado, fortalecimento institucional. O trabalho técnico foi coordenado pela arquiteta Dora Arizaga Gúsman e foi acompanhado de um plano participativo, que levava a comunidade a manifestar-se sobre a proposta. O resultado, além da recuperação patrimonial, significou uma dinamização econômica e de qualidade de vida nas áreas envolvidas ${ }^{3}$.

Para o arquiteto Luiz Antônio B. Custódio, técnico do IPHAN, essa experiência foi vitoriosa porque, além de sua forte base e participação local, os interlocutores equatorianos souberam impor-se ao Banco internacional. Será esta experiência que se tentará reproduzir no Brasil e, depois, na Argentina e no Uruguai (que, ao que parece, já teriam recuado na participação) sem, entretanto, incorporar a participação popular.

Para os países envolvidos, o apoio do órgão financeiro internacional significaria, em termos políticos, um reconhecimento, para além-fronteiras, da qualidade cultural do seu patrimônio arquitetônico, reforçando o orgulho local ${ }^{4}$. Mas, para além da questão político-social, e identitária, ressaltaria as novas possibilidades das áreas de memória como negócio bancário. O financiamento ao Brasil teria alcançado 100 milhões de reais, valores que, aplicados, obrigam a uma contrapartida de $30 \%$, a ser investida pelo tomador local, seja ele público ou privado.

Porto Alegre, escolhida para qualificar-se ao empréstimo, junto com outras 27 localidades, receberá 16 milhões de reais, valor que, se por um lado é considerado módico pelos técnicos que atuam na área patrimonial, por outro lado é a maior quantia já investida nos prédios históricos da cidade 5 .

\section{Turismo como Solução}

A aproximação do Ministério da Cultura com o BID, efetivada na segunda metade dos anos 1990, entretanto, teria raízes filosóficas mais antigas, no período entre 1967-1979. Nesta ocasião, o IPHAN, ainda ligado ao Ministério de Educação e Cultura e sob orientação da Unesco, introduziu no seu discurso institucional questões ligadas ao turismo como forma de carrear fundos para recuperação

3. Entrevista de Luiz Antônio B. Custódio à autora, em maio de 2002.

4. Orgulho localé a expressão que os americanos preferem à identidade, e é aqui utilizada por parecer-nos mais apropriada a tal situação.

5. Para se ter uma idéia, um relatório do IPHAN referente a 1996 registra que o órgão nacional tinha, naquele ano, um orçamento de 16 milhões de reais, sendo que, deste total, $42 \%$ destinava-se à sua própria manutenção administrativa. Em 1997, os valores chegaram a 20 milhões de reais, tendo o administrativo recuado para 30\%. Fonte: Relatório de Atividades IPHAN - 1996-1997. e manutenção tanto de monumentos isolados como de sítios históricos. Ou seja, além das preocupações culturais, passava-se a considerar o lado econômico da sustentabilidade financeira dos prédios, via turismo. Nos anos 1970:

Com o rápido crescimento e transformação do país, foi necessário buscar a preservação de conjuntos urbanos e sítios. Para o desenvolvimento econômico foram tomadas as primeiras iniciativas no âmbito do Turismo Cultural com apoio de consultores da Unesco. (...) Implementou-se um bem estruturado programa de Cidades Históricas, envolvendo pela primeira vez o Ministério do Planejamento, do Interior e do Turismo e foram abertas linhas de financiamento para preservação (Custódio, 2000:183).

O Programa Nacional de Cidades Históricas, com a participação dos ministérios do Planejamento e da Educação, filiava-se à lógica política de um momento em que o país dava ênfase ao planejamento. A preocupação era a de como preservar o patrimônio das cidades brasileiras, em especial as do Nordeste, sob a estagnação financeira. A proposta dos anos 1970 constatou, por um lado, a falta de conhecimento sobre o valor da preservação de bens móveis e imóveis, e, por outro, a necessidade de descentralizar as ações preservacionistas. Havia, ainda, a carência de pessoal técnico especializado, tanto de engenheiros e arquitetos, quanto de artesões para as restaurações.

Os estudos dos anos 1970 geraram pelos menos duas ações práticas: a criação de cursos especializados na Bahia e em Minas Gerais, além da formação de mestres-de-obra no Nordeste, todos eles visando treinar especialistas em conservação e restauração. A proposta ainda envolvia cursos para menores carentes, porque os anos 1970 tinham uma outra preocupação: a consolidação do conceito de bem cultural "e a participação da comunidade na defesa de sua memória coletiva" (Custódio, 2000:183).

Com o decorrer do tempo, as duas filosofias de trabalho - a da busca dos recursos financeiros gerados pelo turismo e a da consolidação participativa da memória coletiva associada a um trabalho técnico qualificado e consistente - não se afirmaram como ações paralelas e interdependentes, mas como políticas que se opunham, e estariam, a partir da década de 1990, em maior tensão. No oposto aos ideais de resgate da nacionalidade via patrimônio cultural nascidos com o Movimento Modernista nos anos 1920, havia o discurso que defendia a sustentabilidade econômica do patrimônio e que via no turismo, segundo Glauco Campello (1998:125) - presidente do Instituto na década de 1990 - "um estímulo à preservação do patrimônio cultural e à sua valorização, sobretudo ao propiciar, ele mesmo, novas formas de usos e vitalização do objeto restaurado". Campello (1998: 125-126) ainda acrescenta: 
A relação do turismo com a preservação é vantiajosa, principalmente, porque é ele que viabiliza, em muitos casos, as grandeis obras de restauro. Mas não é só. É vantajoso também do ponto de vista da vialorização e da visibilidade do bem cultural. A questão que se coloca é a do enfoque dado à restauração de um bem - edifício isolado ou centro históricio, monumento ou acervo de museu - requer, como já dissemos, não só a preservação e a manutenção de seus valores simbólicos como também uma atienção prioritária no seu sentido e conteúdo social. Não basta a recomposição do seu aspecto visual ou cenográfico, como pode parecer suficiente ao turismo.

Embora considere importante a visibilidade: advinda com o turismo, Campello (1998: 126) acusa-o de contentar-se com o cenário, e justifica, em nome dos ideais que vêem no patrimônio o espaço da memória e da identidade coletivos:

\begin{abstract}
[nos centros históricos] os valores histórico e ciultural não estão unicamente no aspecto físico de seus monumentos e arcabjouço arquitetônico. Após sua recomposição, o centro histórico não abrigará somente os novos usos impostos pelo turismo, o que o esvaziaria de seu werdadeiro conteúdo, que também compreende a presença de seus moradorres e da vida no seu dia-a-dia como parte integrante da cidade.
\end{abstract}

A preocupação com a sustentabilidade ećonômica, em 1996, significou a implementação do Programa de Fomento e Apioio à Gestão do Patrimônio Cultural, desencadeado por intermédio da realizaçãio de mesas gerenciais sobre temas como preservação sustentável, cooperação técniica, parcerias etc. Nesse período, o próprio IPHAN anunciava, entre as suas ações ţem-sucedidas e já em desdobramento à visita de Iglesias à Olinda em 1995, qué:

algumas parcerias significativas foram estabeleccidas com diferentes instituiçōes. Com o Banco Interamericano de Desenvclvimento - BID, por intermédio do Ministério da Cultura, visando a execuçāo do projeto Preservação e Revitalização de Núcleos Históricos; com a Embratur e o Serviço de Apoio às Micro e Pequenas Empresas - Sebrae, para a piromoção do desenvolvimento econômico sustentado no Turismo Cultural; e icom o Banco Nacional de Desenvolvimento Econômico e Social e a Compianhia Vale do Rio Doce, para restauração e conservação de monumentos. ([PHAN, 1997: 9)

O arquiteto Luiz Antônio Custódio (2000):180), para quem "se evidencia a importância da preservação dos bens culturais co'mo base para registro, documentação e interpretação dos vestígios da evolução e do desenvolvimento dos grupos humanos", constata que, já há algum tempo, a irniciativa privada brasileira desco- briu a cultura como uma boa fonte de negócios, independente das questões de sustentabilidade, memória ou identidade nela implícitas.

Isso teria acontecido, em especial, a partir do governo Collor de Mello, quando a Lei Sarney de apoio à cultura foi substituída pela Lei Rouanet - Lei no 8.313 e sua política de renúncia fiscal, ou seja, o poder público abrindo mão de parte de arrecadação para que essa fosse encaminhada a projetos específicos. A renúncia fiscal significa que o governo transfere não apenas recursos financeiros, mas a própria gestão, a prioridade e os objetivos dos assuntos e das políticas culturais para os grandes grupos financeiros, porque serão eles, em última instância, que escolherão quais produtos culturais "merecem" apoio financeiro.

Não por acaso, nas últimas décadas, vários bancos e outras instituições financeiras transformaram-se em agentes beneméritos da cultura nacional, em que pese no mais das vezes essa ação materializar-se em edifícios luxuosos - denominados centros culturais - construídos ou restaurados em pontos comerciais valorizados das grandes cidades brasileiras, como a avenida Paulista, em São Paulo. Essas ações, independente do que venham a reverter à cultura local e/ou nacional, ampliam e qualificam o patrimônio imobiliário das instituições mecenas. Outro destino dessas verbas tem sido a edição de publicações luxuosas, gerenciadas a partir dos departamentos de marketing e destinadas a clientes seletos. Nessa linha, o patrimônio torna-se um fator de exposição pública e a cultura um marketing extremamente barato para as instituições, pois, em última análise, é uma ação sustentada por dinheiro público via renúncia fiscal.

A redução de investimentos incentivou o desenvolvimento de parcerias, buscando a sustentabilidade do patrimônio. A implantação das leis de incentivo à cultura propiciou novas alternativas de financiamento ao setor. Ao mesmo tempo, tem proporcionado o patrocínio de obras tecnicamente questionáveis em importantes centros históricos, principalmente no Nordeste. É o caso de cenários de patrimônio, como os do Pelourinho em Salvador ou outros semelhantes, caracterizados por reformas de fachada (Custódio, 2000:184).

Tal política de mecenato substitui, ainda segundo Custódio, recursos que eram aplicados nos Estados e Municípios por ação direta do poder público, com critérios técnicos pontuais e, pelo menos em princípio, menos políticos. Agora, os "prefeitos vão direto para Brasília, não precisam passar pelo órgão regional",

6. Luiz Antônio Custódio, em entrevista à autora, em março de 2002. 
tornando a negociação política muito maior. Ou, se for o caso, os prefeitos vão direto aos bancos na busca de linhas de crédito, ou às grandes empresas, na busca de parcerias culturais.

\section{Monumenta e sua Viabilização Econômica}

Quando da aproximação do Ministério da Cultura com o Banco Interamericano de Desenvolvimento, em 1996, o ministro contratou uma empresa privada para a elaboração do projeto solicitado pela instituição financeira, na impossibilidade do IPHAN realizar tal tarefa em tempo hábil. A contratação foi feita via convênio com a instituição internacional, a Unesco, para burlar a Lei de Licitações, "o que acarreta, também, pagamentos e custos internacionais".

Contratados gestores externos, a proposta do Monumenta passou a ser discutida fora do IPHAN, pois precisava de "autonomia e independência". Técnicos e consultores do BID participaram para desenhar, configurar e priorizar o processo. O BID trás muita gente, embora as intervenções financiadas dentro do Monumenta devam ter projeto, orçamento e detalhamento técnico aprovados pelo IPHAN, que, na era do desmonte das instituições públicas, não possui pessoal em número suficiente para atender as demandas que o projeto vai gerar ${ }^{8}$.

Ainda segundo Custódio:

como as localidades disputam a indicação para participar do Monumenta, boa parte do dinheiro é gasto para enquadrá-la nas solicitações do projeto, entre outros, contratando consultores ${ }^{9}$.

$\mathrm{Na}$ avaliação do arquiteto, na melhor das hipóteses apenas $60 \%$ do valor contratado com o BID resultará em obras de fato. Em Porto Alegre, a contraparte prevista para investimento da Prefeitura envolve, justamente, a contratação de estudos sobre o mercado imobiliário, estudos de viabilidade econômico-financeira e de viabilidade técnica, e estudos do perfil da população.Incluídos todos os estudos, o documento final da capital gaúcha deverá ter cerca de oito volumes.

$\mathrm{Na}$ lógica defendida por patrimonialistas como o arquiteto Luiz Antônio B. Custódio, "patrimônio é documento. Estragou, não conta mais história" ${ }^{10}$.

7. Idem.

8. Idem.

9. Idem.

10. Idem.
Por esta razão, técnicos e operários devem ser especializados e competentes ao extremo, o que representa um obstáculo quando as obras são contratadas por licitação e ao critério do menor preço, ou quando os consultores externos contratados desejam encerrar sua participação com a máxima brevidade e, por serem externos, não possuem maiores vínculos com as localidades. Outro problema é a falta de pessoal especializado: "Ouro Preto, por exemplo, não tem nenhum técnico habilitado para o processo" 1 .

Para Custódio, o próprio conceito Monumenta, a denominar o programa, já é em si equivocado: "monumento é um termo e um conceito superado", quando a nova visão prega a revitalização de sítios urbanos e, neles, de um contexto e de um conjunto. Outra lógica equivocada do Monumenta, além do conceito, seria o propor a sustentabilidade, uma vez que, mesmo na França, com seus 70 milhões de turistas ao ano, "há bens sustentáveis e bens sustentados. A Torre Eiffel é sustentável. Notre Dame sempre será sustentada. Mas as duas, igualmente, beneficiam hotéis e restaurantes"12.

Centrado na questão econômica, o Monumenta estrutura-se com especificidades:

sua prioridade são os bens que necessitam de restauração; está baseado no princípio da sustentabilidade, ou seja, o prédio recuperado deve ter uso que dê retorno financeiro epermita sua conservação ao longo do tempo; um dos seus objetivos principais é proteger o patrimônio federal, estadual e municipal, nesta ordem ${ }^{13}$.

Nesses termos, segundo a coordenadora do projeto em Porto Alegre, arquiteta Briane Bicca, uma primeira etapa antecedeu o envio da proposta da cidade ao Ministério da Cultura. Para atender a exigência do órgão federal às cidades participantes no sentido de que, no local, haja prédios tombados pela União, Porto Alegre iniciou a busca por qualificar-se neste item - até então, havia apenas quatro imóveis nesta situação na cidade ${ }^{14}$ - e encaminhou processo solicitando o tombamento de prédios e sítios. O tombamento solicitado foi aprovado em 9 de novembro de 2000 , e incluía sete prédios $^{15}$ na área delimitada para interferência

11. Idem.

12. Idem.

13. Conforme o folheto Programa Monumenta - Porto Alegre.

14. Segundo o Relatório de Atividades IPHAN - 1996- 1997 (p. 5), nesta oportunidade haveria um universo de 16 mil edifícios tombados, sob a guarda das diversas unidades do órgāo federal.

15. Os prédios tombados nesse momento: Portāo do Cais do Porto e dois armazéns contíguos, Museu de Arte do RS, Memorial do RS, Biblioteca Pública, Palácio Piratini e Theatro Sāo Pedro. 
do Monumenta, além das praças da Alfândega e da Matriz e seus entornos, que passaram a ser considerados como sítios históricos.

No que se refere a prédios de propriedade privada, a adesão à proposta não significa restrição de uso ou propriedade, pelo contrárío: o espaço recuperado deverá ser utilizado para fins comerciais ou de moradia, em nome da sua sustentabilidade. Não há impedimento, também, a que o imóvel venha a ser futuramente comercializado. Os empréstimos recebidos por particulares terão um prazo de carência de seis meses após o início da obra, e 120 meses para pagamento, se forem comerciais, e 150 meses no caso dos residenciais, valores sobre os quais não incidirão juros, apenas pequena taxa de serviço.

Esses valores, à medida que forem devolvidos, irão alimentar um Fundo Municipal, a ser criado junto à Secretaria Municipal da Cultura de Porto Alegre, com o objetivo de reaplicação dos valores na preservação dos demais prédios listados como de interesse patrimonial na área, ou mesmo para complementação de obras nos prédios originalmente já financiados. Na leitura do arquiteto Custódio, esta seria uma maneira de "criar lucro, criar dinheiro, para que o governo se retire", pois o governo federal assumiria o pagamento do empréstimo original junto ao BID, mas eximir-se-ia de outras participações futuras em prol do patrimônio local, embora isso não seja uma colocação explícita nos documentos.

Segundo Briane Bicca, as regras do BID não puderam ser discutidas pelos participantes. Entre essas regras, um dos conceitos básicos do programa do Banco, além do de sustentabilidade, é o de atratividade, que implica selecionar ações que melhor contribuam para esse fim, ou seja, no jargão da Carta Consulta Parecer Técnico ${ }^{16}$, o de "destacar a implantação de usos comerciais, turísticos e culturais", em especial junto ao Pórtico Central do Cais do Porto e no entorno da Praça da Alfândega, no caso de Porto Alegre.

\section{Monumenta: acessibilidade, sustentabilidade e visibilidade}

Outro conceito destacado do Monumenta é o de acessibilidade, que corresponde à melhoria das condições de acesso à área, para tanto recomendando a implantação de estacionamento para veículos individuais e coletivos turísticos, e o alargamento e a melhoria de passeios e travessias de pedestres. A acessibilidade, entretanto, não é universal, mas seletiva: outro documento, a Carta Consulta

16. Documento aprovado pelo Comitê de Avaliaçāo do Monumento e assinado a pelo seu presidente e coordenador nacional, Pedro Tadei Netto, em Brasília, em 12 de julho de 2001. de Porto Alegre, em sua página 20, registra o fato de várias linhas de ônibus urbanos terem seu terminal na avenida Sepúlveda - em plena área do Projeto - e que isto prejudica a qualidade paisagística e a ambiência, devendo, pois, serem remanejadas para outros locais. Ou seja, a acessibilidade não supõe todos os segmentos da população, mas daqueles que se deslocam em carro de passeio ou veículo turístico.

Quanto à participação privada no Programa, em complementação aos aportes públicos, segundo os documentos técnicos, esta vai além da recuperação dos imóveis e supõe ações de promoção de atividades econômicas, culturais e turísticas, pois a área elegivel objeto das intervenções deve "representar um conjunto organicamente estruturado, tanto do ponto de vista urbanístico, quanto econômico"17, atendendo a outro conceito-chave da proposta, a já citada sustentabilidade econômica.

O Monumenta é um programa de recuperação sustentável do patrimônio histórico urbano brasileiro sob tutela federal, resultado de contrato de empréstimo entre o BID e a República. Por recuperação sustentável entende-se a execução de obras de conservação e restauração e de medidas econômicas, institucionais e educativas, para ampliar o retorno econômico e social dos investimentos do programa, aplicando-os em sua conservação permanente ${ }^{18}$.

Para que não haja dúvida quanto ao termo, a proposta esclarece que por sustentabilidade entende-se que os "investimentos em monumentos públicos sob proteção estadual ou municipal devem apresentar taxa de retorno igual ou superior a $12 \%$ ao ano, a preços constantes" ${ }^{\prime \prime}$, e o mesmo se espera dos bens particulares. Exemplos de iniciativas sustentáveis do setor privado seriam as ações que requalificam prédios instalados no sítio histórico, transformando-os em centros culturais. Outras possibilidades seriam a cobrança de ingressos para acesso aos prédios, mesmo que a preços reduzidos.

Quanto à acessibilidade, a Carta Consulta de Porto Alegre apresentada ao Ministério da Cultura destaca, ainda, que o aeroporto local - o Salgado Filho -, recebe três milhões de passageiros/ano e 140 vôos diários, além de localizar-se a seis quilômetros do sítio histórico; o mesmo documento acrescenta que uma importante malha rodoviária facilita o acesso ao local. Com estas informações, parece estar assegurada a sustentabilidade, colocando o Centro Histórico como oferta turística a esses visitantes potenciais. A busca pela atratividade está implícita em

17. Texto do documento Projeto Porto Alegre/RS - Carta Consulta, de junho de 2001.

18. Idem.

19. Idem 
toda a proposta, como ao direcionar financiamento para a restauração da fachada - a face do prédio que dá para a rua -, e não para o imóvel como um todo. Segundo a arquiteta Briane, o objetivo é que "o imóvel retorne às feições originais, mas adequado aos novos níveis (sic) de necessidade" ${ }^{20}$. Na mesma linha, para maior visibilidade, os prédios monumentais receberão iluminação cênica, as calçadas serão alargadas e ganharão tratamento paisagístico.

Para além das normas impostas pelo BID, e que estavam acima de discussão, a versão do Monumenta Porto Alegre propõe resgatar a afetividade do cidadão em relação ao espaço histórico, promovendo a convivência de épocas, de culturas, etnias e segmentos sociais ${ }^{21}$, dando continuidade à proposta que vem sendo implementada na cidade pelo Projeto Corredor Cultural - Rua da Praia, desde 1996. Esta proposta possui quatro eixos de ação: qualificação do espaço público, preservação do patrimônio cultural, revitalização econômica e animação cultural ${ }^{22}$, partindo da constatação de que, na área: 1) a população não estaria se apropriando do patrimônio cultural urbano; 2) o patrimônio cultural não estaria preservado na íntegra. A Carta Consulta parte desta situação problemática, propondo alcançar uma situação futura desejável, no jargão do planejamento.

A revitalização incluiria:

(...) conjunto de ações e atividades destinadas à recuperação, restauração ou reutilização de espaços públicos e do conjunto monumental, qualificação de serviços e infra-estrutura urbana e a preparação de ambientes e roteiros temáticos para desenvolvimento do Turismo Cultural ${ }^{23}$.

É nessa perspectiva que a animação cultural seria utilizada como ferramenta de integração entre a população e o sítio histórico. Entre outras, há propostas de incentivo à realização de eventos como feiras, teatro de rua e exposições a céu aberto.

\section{Considerações Finais}

O Programa Monumenta pode significar um importante incremento ao turismo nas áreas em que for implantado, mas para que isso venha a acontecer,

20. Briane Bicca, em entrevista à autora, em março de 2002

21. Carta Consulta.

22. Idem.

23. Documento: Programa Monumenta - Projetos RS (1999), da 12º Superintendência Regional/ IPHAN/MinC. seria recomendável que o projeto fosse acompanhado de ações mais amplas de planejamento turístico, para que, desde o início, os técnicos capacitados a pensar a cultura e o patrimônio local pudessem fazê-lo não apenas sob o ponto de vista de sua atratividade, mas também dos cuidados e das ações que devem acompanhar a busca de sustentabilidade (não apenas econômica), sendo ouvidos e dando a sua contribuição à proposta. Hoje, diferentes propostas de turismo, em especial a cultural, desenvolvidas em várias regiões do planeta, permitem um acúmulo de experiências e um acúmulo teórico que, com certeza, qualificariam a aplicação dos investimentos do Programa Monumenta nos municípios brasileiros.

\section{Referências Bibliográficas}

BARRETTO, Margarita. 2000. Turismo e legado cultural. São Paulo: Papirus. CHOAY, F. 2000. A alegoria do patrimônio. Lisboa: Ediçōes 70.

CUSTODIO, Luiz A. B. 2000. Patrimônio edificado: conservação e ética. Ciência e Letras, Porto Alegre, no 27, p. 3-349, jan./jun.

DOBERSTEIN, A. 1992. Estatuária e ideologia. Porto Alegre: Prefeitura Municipal/SMC.

ESPERANÇA, Eduardo Jorge. 1997. Patrimônio: comunicação, políticas e práticas culturais. Lisboa: Veja Universidade.

HERBERT, D. 1995. Heritage, tourism and society. London: Mansell.

HUYSSEN, Andreas. 2000. Seduzidos pela memória. Arquitetura, monumentos, mídia. Rio de Janeiro: Aeroplano.

INSTITUTO DO PATRIMÔNIO HISTORICO E ARTÍSTICO NACIONAL. 1997. Relatório de atividades 1996-1997. Brasília.

IPHAN. Relatório de atividades 1996-1997.

LE GOFF, Jacques. 1988. Por amor às cidades. São Paulo: Unesp.

LYNCH, Kevin. 1997. A imagem da cidade. São Paulo: Martins Fontes.

MARTINI, M. Luiza. 1997. Corredor Cultural - Rua da Praia. Porto Alegre: Unidade Editoral/SMC. MUMFORD, L. 1998. A cidade na história. São Paulo: Martins Fontes.

PORTO ALEGRE, Prefeitura Municipal. 1992. Memória e identidade. SMC/SMED.

PORTO ALEGRE, Prefeitura Municipal. 2001. A memória cultural numa cidade democrática. Porto Alegre: Unidade Editorial/SMC.

PORTO ALEGRE, Prefeitura Municipal. 2000. Museologia social. Porto Alegre: Unidade Editorial/SMC.

Recebido em 28/07/2003. Aprovado em 01/09/2003 